\title{
QUANTUM CHEMICAL STUDY OF ORGANIC DYE SENSITIZED SOLAR CELLS: 4,4-BIPYRIDINE DERIVATIVES
}

\author{
S. Mohan Kumar ${ }^{1, *}$, T. Kannaian ${ }^{1}$ and V.Sathyanarayanamoorthi ${ }^{2}$ \\ ${ }^{1}$ P.G. and Research Department of Electronics, PSG College of Arts and Science, \\ Combatore-641 014, Tamilnadu, India \\ ${ }^{2}$ P.G. and Research Department of Physics, PSG College of Arts and Science, \\ Combatore-641014, Tamilnadu, India \\ *E-mail: mohanmeghas@gmail.com
}

\begin{abstract}
The electronic structure and excitation properties of the Dipyridyl dye molecule and its derivatives were performed using the Gaussian 09 software package. Calculations were performed based on the framework of density functional theory (DFT) with the Becke 3-parameter-Lee-Yang-Parr (B3LYP) functional, where the 6-311+ G (d,p) basis set was employed. The HOMO-LUMO energy gap, the improved light harvesting efficiency(LHE) and free energy change of electron injection of newly designed sensitizers revealed that this material would be an excellent sensitizer. Each of the molecules was theoretically analyzed and these could help in designing more efficient functional dye-sensitizers.
\end{abstract}

Keywords : DSSC, Dipyridyl, Organic dyes

(C) RASĀYAN. All rights reserved

\section{INTRODUCTION}

Dye-sensitized solar cells (DSSC) is a low cost solar cell and it attain more consideration because of its sky-scraping light to electricity conversion efficiency. ${ }^{1-3}$ The sensitizer is a critical element in DSSC, which improves the power conversion efficiency and increases the stability of the devices. Searching and developing of renewable energy sources can be done only by solar cells, which serves as an answer to the global challenge. Photovoltaic technologies become the scientific topic of interest, in the systems of solar to electrical energy conversion cell. Dye sensitized solar cell(DSSC) are contemplated for this work. We evaluate dye properties with $\mathrm{TiO}_{2}$. 4,4'-Bipyridine (4,4'-bipy) is mainly used as a precursor to the $N, N^{\prime}$ dimethyl-4,4'-bipyridinium dication commonly known as paraquat. This species is redox active, and its toxicity arises from its ability to interrupt biological electron transfer processes. Because of its structure, 4,4'-bipyridine can bridge between metal centers to give coordination polymers. Among the various dyes being investigated, the dipyridine has been considered due to its unique opto-electrical properties. As such, we consider it important to understand the similarities and scope between their properties which can be used for DSSC.

\section{EXPERIMENTAL}

GAUSSVIEW software was used to generate the molecular structures, and calculations were performed using GAUSSIAN 09W. ${ }^{4}$ Density functional theory (DFT) was implemented in the frequency and energy optimization. Time-dependent DFT (TD-DFT) was employed the same level of theory, the 6-311G (d, p) basis set and the Becke3-parameter -Lee-Yang-Parr (B3LYP) functional were employed. Polarizable continuum model (PCM) was used to study solvent effects.

The free energy change for electron injection onto a titanium dioxide surface is:

$$
\Delta G^{\text {inject }}=E_{o x}^{d y e *}-E_{C B}^{T i O 2}
$$

where $E_{o x}^{d y{ }^{*} *}$ is the oxidation potential of the dye in the excited state and $E_{C B}^{T i O 2}$ is the energy of the conduction band of the $\mathrm{TiO}_{2}(-4.0 \mathrm{eV})$ semiconductor. ${ }^{5}$ The model used for the evaluation of $E_{\text {ox }}^{\text {dye* }}$ 
implies that the electron injection occurs from the unrelaxed excited state. For this reaction path, the excited-state oxidation potential can be extracted from the redox potential of the ground state $E_{o x}^{d y e}$, and the absorption energy associated with the photo-induced ICT $\left(\lambda_{\max }^{I C T}\right)$ according to:

$$
E_{\text {ox }}^{\text {dye* }}=E_{\text {ox }}^{\text {dye }}-\lambda_{\max }^{I C T}
$$

Where, $\lambda_{\text {max }}^{I C T}$ is the energy of the intermolecular charge transfer.

The efficiency of DSSC is the performance of the dyes in responsibility to the incident light. Based on the light harvesting efficiency (LHE) of the dyes, the value has to be as high as possible to maximize the photocurrent response. The light harvesting efficiency (LHE) was determined by a formula. ${ }^{6}$

$$
\mathrm{LHE}=1-10^{-f}
$$

Where, $f$ is the Oscillator's strength of the dye.

\section{RESULTS AND DISCUSSION}

New sensitizers for DSSC application was designed based on the study that was carried out. The designed dyes consist of following parts: Auxiliary Donor (AD), Donor (D), Pi-Spacer $(\pi)$ and Acceptor (A) as shown in figure 1 . We have made the structural modification of 4,4-Dipyridyl for designing the new dyes. The structure of Dipyridyl and newly designed dyes is shown in Figures- 1 and 2.

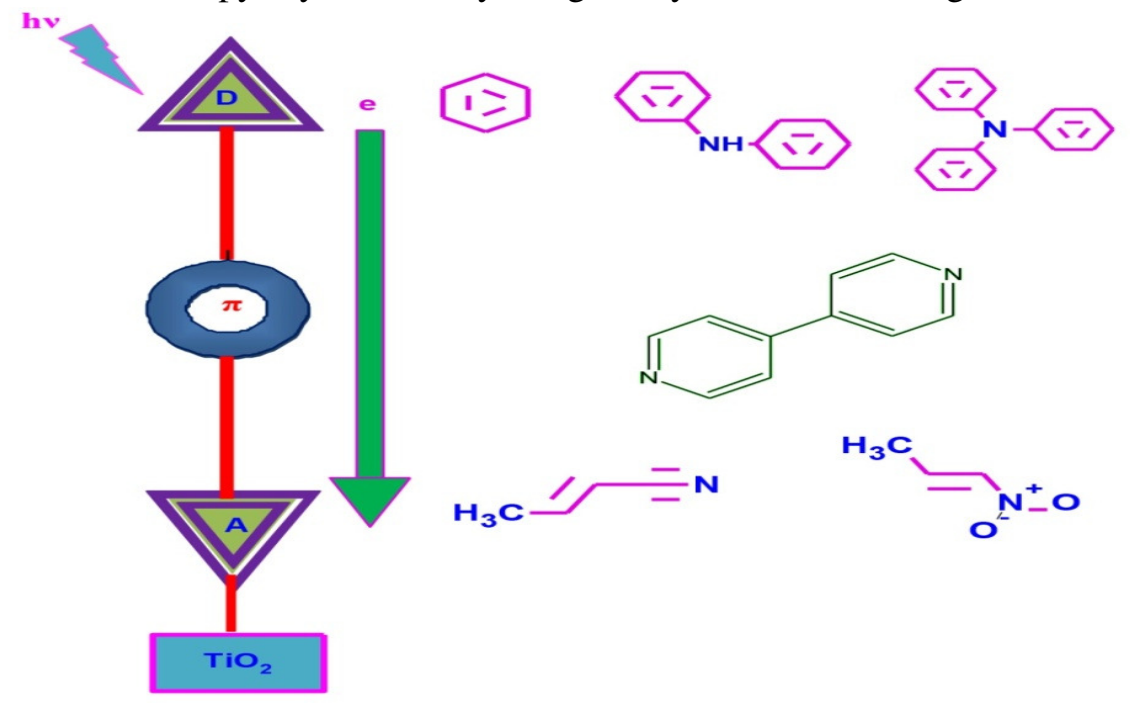

Fig.-1: Different parts of D- $\pi$-A system, $D=$ donor, $\pi=$ pi-spacer, $A=$ acceptor

The ground state structures for all molecules were with B3LYP/6-311+G(d,p) level. The discussion about geometrical parameters of the ground state structure is neglected for all the molecules and they have not imaginary frequencies. The highest occupied molecular orbital energies ( $\mathrm{E}_{\text {номо) }}$ and the lowest unoccupied molecular orbital energies ( $\mathrm{E}_{\mathrm{LUMO}}$ ) of all dyes computed at the B3LYP/6-311+G(d,p) level in the gas and DMF are listed in Table-1. The distribution pattern of highest occupied molecular orbitals (HOMO) and lowest unoccupied molecular orbitals (LUMO) are used to study the efficiency of sensitizers.

Table-1: The $\mathrm{E}_{\mathrm{HOmo}}, \mathrm{E}_{\mathrm{Lumo}}$ and energy gap (Eg) of dyes in $\mathrm{eV}$ at B3LYP/6-311+G level of theory

\begin{tabular}{c|c|c|c|c|c|c}
\hline \multirow{2}{*}{ System } & \multicolumn{3}{|c|}{ Gas Phase } & \multicolumn{2}{c}{ DMF } \\
\cline { 2 - 7 } & $\mathrm{E}_{\text {HOMO }}$ & $\mathrm{E}_{\text {LUMO }}$ & $\mathrm{E}_{\text {gap }}$ & $\mathrm{E}_{\text {HOMO }}$ & $\mathrm{E}_{\text {LUMO }}$ & $\mathrm{E}_{\text {gap }}$ \\
\hline POT & -6.9239 & -1.8484 & 5.0755 & -6.9871 & -1.9192 & 5.0678 \\
\hline POT1 & -6.0929 & -2.5540 & 3.5388 & -6.0739 & -2.5031 & 3.5707 \\
\hline
\end{tabular}


RASĀYAN J. Chem.

Vol. 10 | No. 2 |613-620 | April - June | 2017

\begin{tabular}{c|c|c|c|c|c|c}
\hline POT2 & -6.1944 & -2.7685 & 3.4259 & -6.1465 & -2.9940 & 3.1524 \\
\hline POT3 & -7.4336 & -1.4438 & 5.9898 & -5.9664 & -2.9715 & 2.9949 \\
\hline POT4 & -5.9661 & -2.4329 & 3.5331 & -5.9269 & -2.4169 & 3.5100 \\
\hline POT5 & -6.7703 & -1.8028 & 4.9675 & -6.8026 & -1.9200 & 4.8825 \\
\hline
\end{tabular}
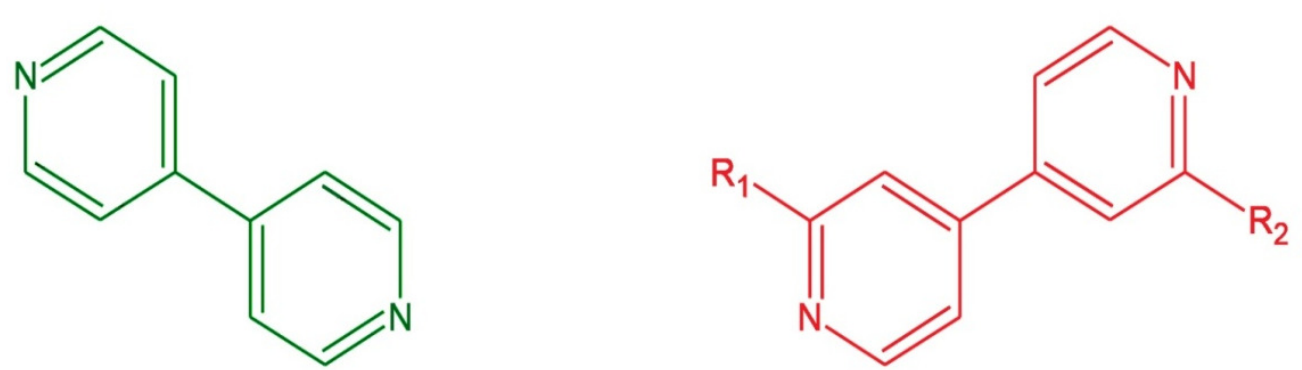

$\begin{array}{ll}\text { DP1 } & \mathrm{R}_{1}=\mathrm{C}_{2} \mathrm{H}_{2} \mathrm{CN} \\ \text { DP2 } & \mathrm{R}_{1}=\mathrm{C}_{2} \mathrm{H}_{2} \mathrm{NO}_{2} \\ \text { DP3 } & \mathrm{R}_{1}=\mathrm{C}_{2} \mathrm{H}_{2} \mathrm{CN} \\ \text { DP4 } & \mathrm{R}_{1}=\mathrm{C}_{2} \mathrm{H}_{2} \mathrm{NO}_{2} \\ \text { DP5 } & \mathrm{R}_{1}=\mathrm{C}_{2} \mathrm{H}_{2} \mathrm{CN}\end{array}$

$$
\begin{aligned}
& \mathrm{R}_{2}=\mathrm{C}_{12} \mathrm{H}_{10} \mathrm{~N}-\mathrm{COCH}_{3} \\
& \mathrm{R}_{2}=\mathrm{C}_{12} \mathrm{H}_{10} \mathrm{~N}-\mathrm{COCH}_{3} \\
& \mathrm{R}_{2}=\mathrm{C}_{12} \mathrm{H}_{10} \mathrm{~N} \\
& \mathrm{R}_{2}=\mathrm{C}_{12} \mathrm{H}_{10} \mathrm{~N} \\
& \mathrm{R}_{2}=\mathrm{C}_{18} \mathrm{H}_{14} \mathrm{~N}
\end{aligned}
$$

Fig.-2: Chemical structure of 4,4-Dipyridyl [DP] and newly designed dyes.

From the Figs.-3 and 4 it is clear that HOMOs are present on auxiliary group while LUMOs are present on the benzene ring of Dipyridyl near the anchoring group. Such electron density distribution is beneficial for efficient charge separation and electron injection. This indicates the charge transfer from donor to acceptor through Pi-spacer significance. Charge transfer from donor to acceptor proved that DP4 provides best dye which serves as brilliant sensitizers. By comparing the energy gaps of Dipyridyl and newly designed dyes, in both gas phase and DMF using Figs.-5 and 6, DP4 provides least energy gap. This may happen due to the substitution of the electron donating group, at DPA and with drawing groups and acceptor sides leads to efficient electron transfer which enhances the efficiency of dye DP4.

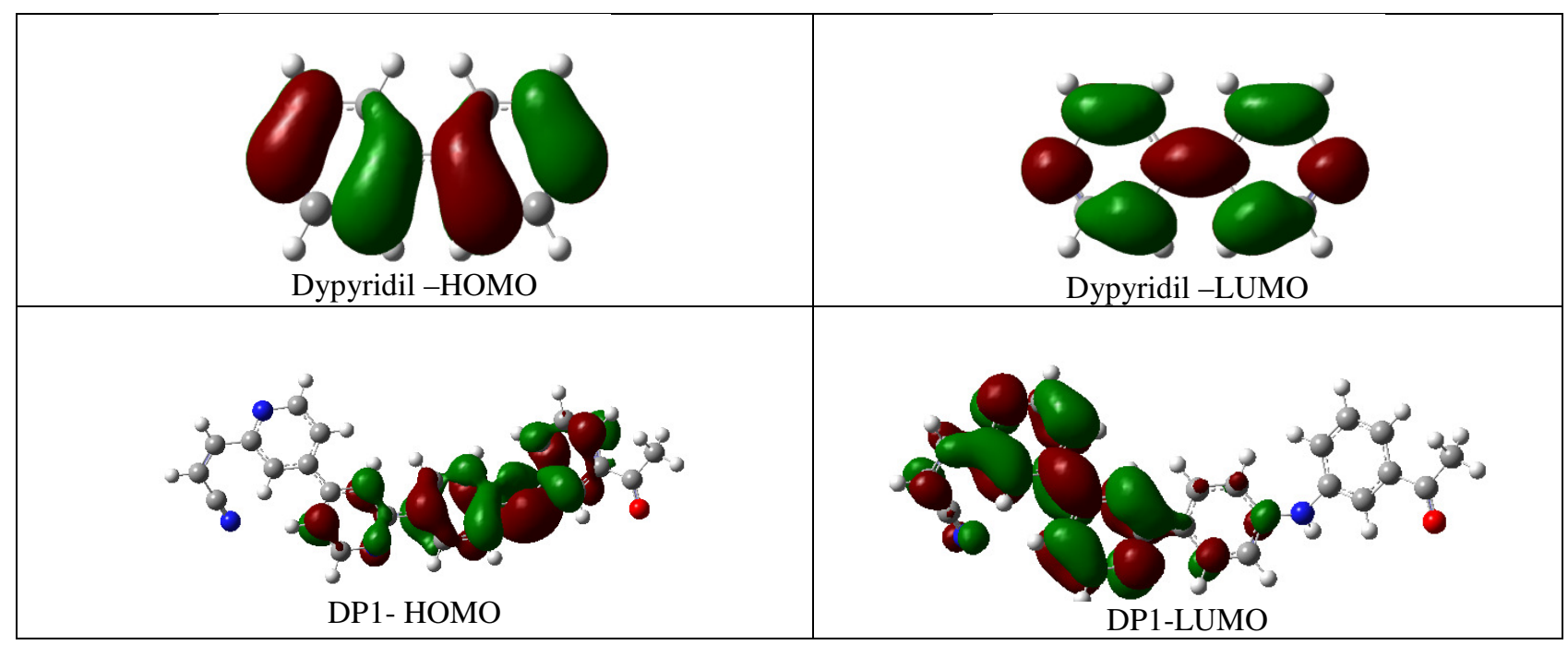


RASĀYAN J. Chem.

Vol. 10 | No. 2 |613 - 620 | April - June | 2017

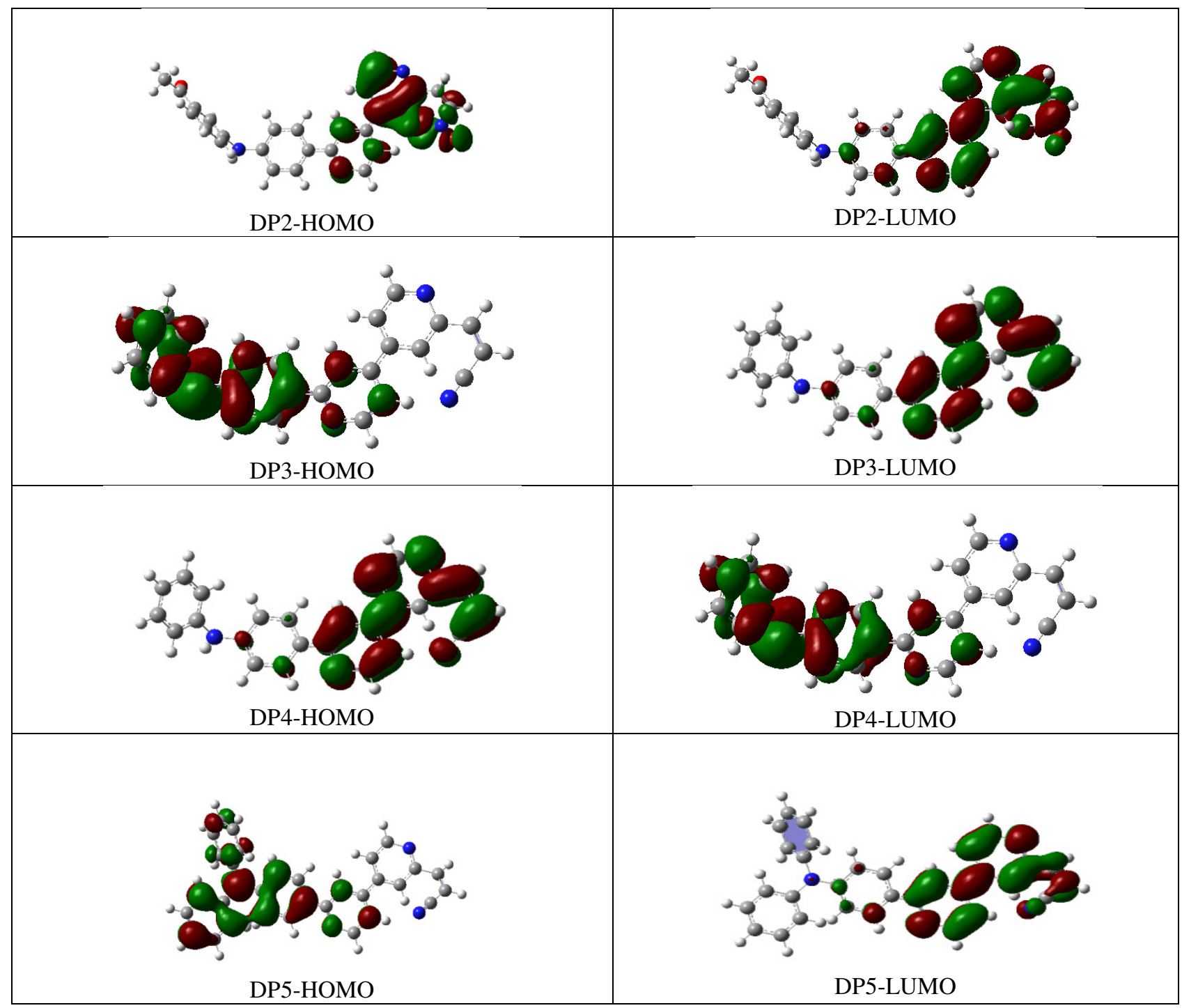

Fig.-3: The HOMO and LUMO distribution pattern of dyes at DFT / B3LYP/6-311+G(d,p) level of theory in gas

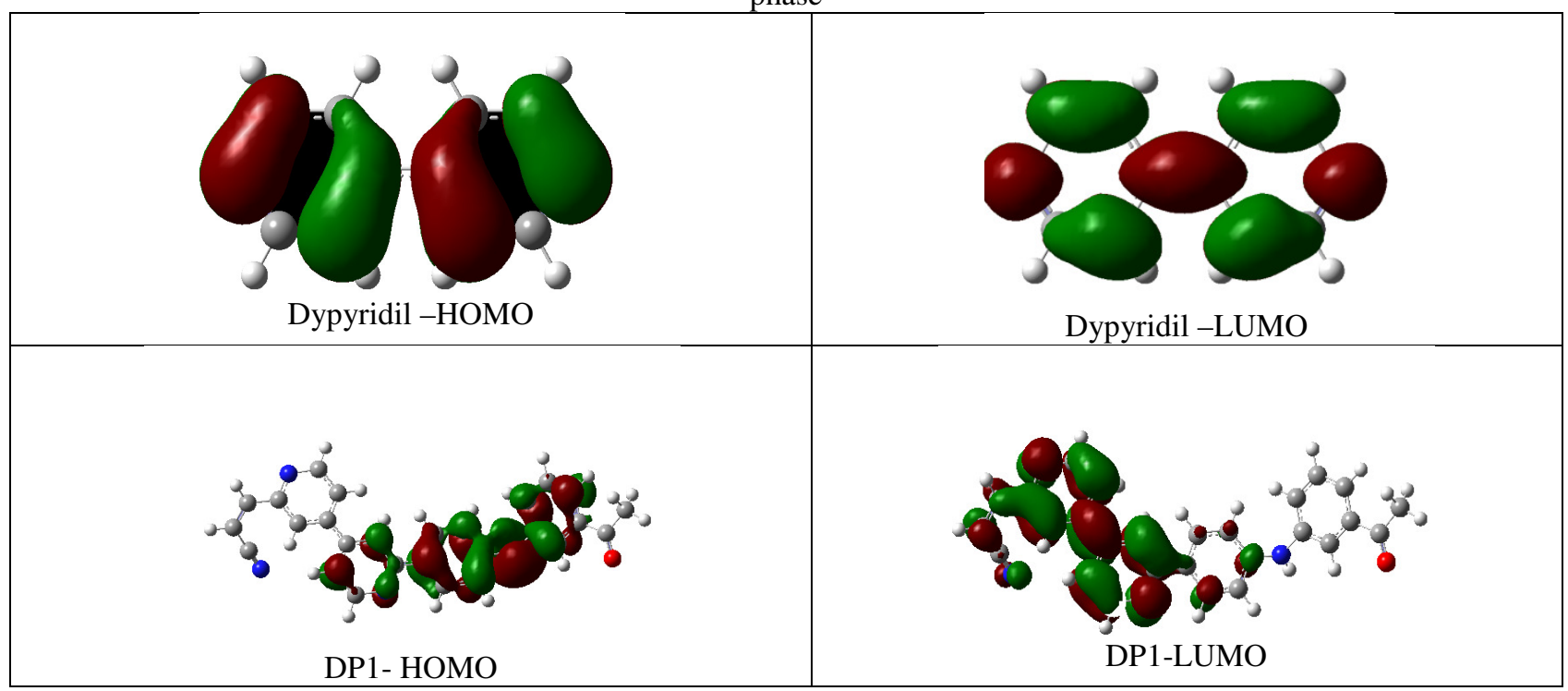




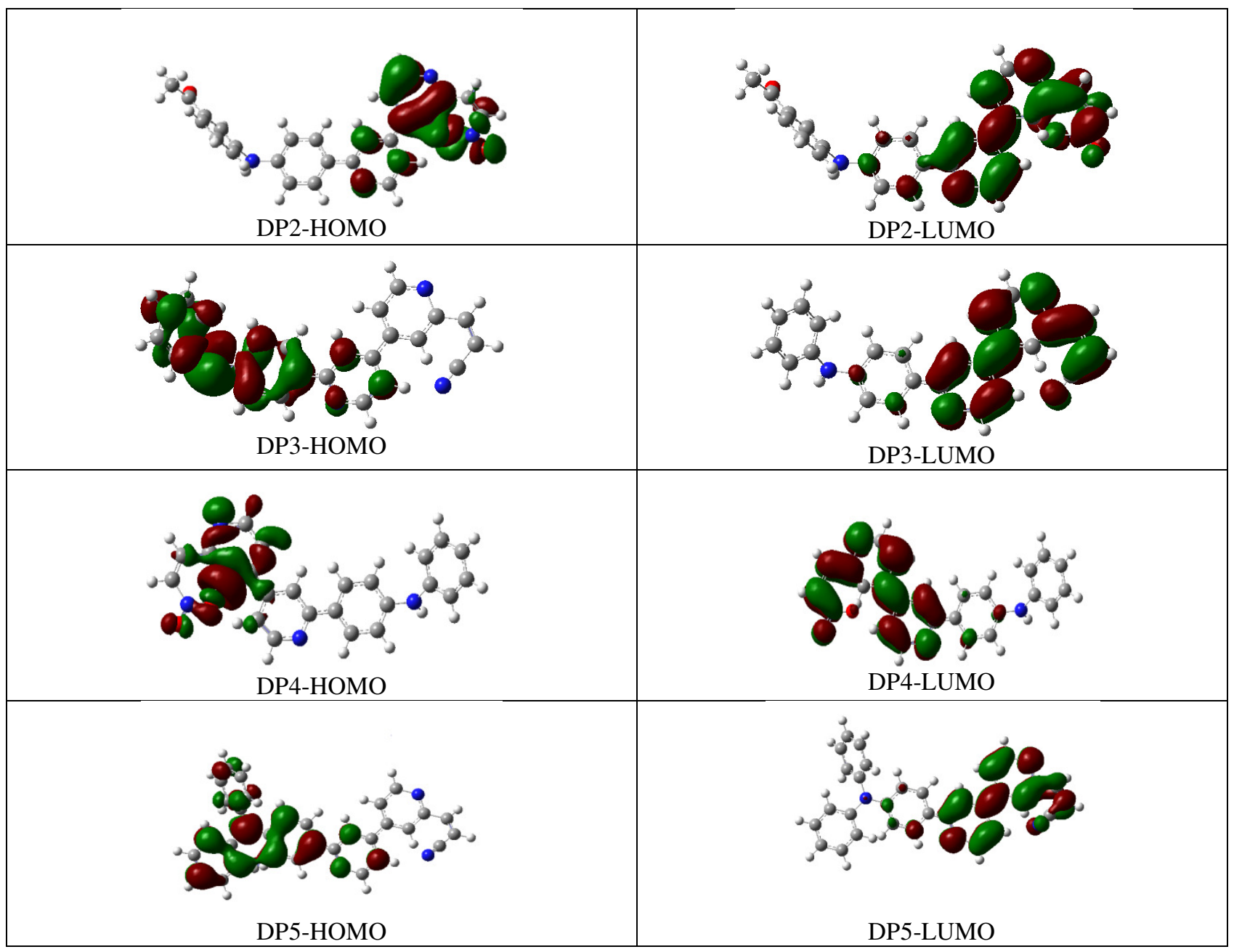

Fig.-4: The HOMO and LUMO distribution pattern of dyes at DFT / B3LYP/6-311+G* level of theory in PCM.

Free Energy Change of Electron Injection and Oxidation Potential Energy

We have used mathematical equations to estimate the dye's excited state oxidation potential and free energy change of electron injection in titanium dioxide (TiO2) surface. $\lambda_{\max }, \Delta \mathrm{G}^{\text {inject }}, \lambda_{\max }{ }^{\mathrm{ICT}}, \mathrm{E}_{\mathrm{Ox}}{ }^{\text {dye }}$, $E_{O X^{d y e *}}$ are presented in Table 2 . The electron injection free energy change $\Delta \mathrm{G}^{\text {inject }}$, ground and excited state oxidation potential $\mathrm{E}_{\mathrm{ox}}{ }^{\mathrm{dye}} \mathrm{e}^{*}$ are computed in gas phase and DMF respectively. The $6-311+\mathrm{G}^{*}$ basis set is used for all calculations. $\mathrm{E}_{\mathrm{OX}}{ }^{\text {dye }}$ can be estimated as negative $\mathrm{E}_{\text {Номо. }}{ }^{7,8} \mathrm{E}_{\mathrm{OX}}{ }^{\text {dye* }}$ is calculated based on Eq. (2) $\Delta G^{\text {inject }}$ was estimated using Eq.-1. Its values are negative for all dyes. In parent molecule $\Delta G^{\text {inject }}$ is -1.027 in the gas phase while it is -1.004 in DMF because of lowering of LUMO energy in solvent phase. In all new designed dyes DP1,DP2 and DP3 $\Delta \mathrm{G}^{\text {inject }}$ improved in solvent phase as shown in Table 2. The negative $\Delta \mathrm{G}^{\text {inject }}$ is an indication of spontaneous electron injection from the dye to TiO2. For all newly designed dyes $\Delta \mathrm{G}^{\text {inject }}$ is negative. The Order of $\Delta \mathrm{G}^{\text {inject }}$ is: DP4 $>\mathrm{DP}>\mathrm{DP} 1>\mathrm{DP} 3>\mathrm{DP} 2$.

Table-2: Calculated absorption spectra $\lambda_{\max } \mathrm{nm}, \Delta \mathrm{G}^{\text {inject }}$, oxidation potential, intramolecular charge transfer energy of dyes at B3LYP/6-311+G level of energy

\begin{tabular}{c|c|c|c|c|c|c|c|c|c|c}
\hline & \multicolumn{5}{|c|}{ Gas Phase } & \multicolumn{3}{c}{ DMF } \\
\hline System & $\lambda_{\max }$ & $\Delta G^{\text {inject }}$ & $E_{\text {ox }}^{\text {dye }}$ & $E_{\text {ox }}^{\text {dye }}$ & $\lambda_{\max }^{\text {IT }}$ & $\lambda_{\max }$ & $\Delta G^{\text {inject }}$ & $E_{\text {ox }}^{\text {dye* }}$ & $E_{\text {ox }}^{\text {dye }}$ & $\lambda_{\max }^{I C T}$ \\
\hline DP & 306.85 & -1.027 & 2.9723 & 7.0129 & 4.0406 & 308.31 & -1.004 & 2.996 & 7.0175 & 4.0215 \\
\hline DP1 & 361.45 & -1.337 & 2.623 & 6.0532 & 8.430 & 259.87 & -0.5833 & 8.4167 & 8.1876 & 4.7709 \\
\hline
\end{tabular}


RASĀYAN J. Chem.

Vol. 10 | No. 2 |613-620 | April - June | 2017

\begin{tabular}{c|c|c|c|c|c|c|c|c|c|c}
\hline DP2 & 447.59 & -0.8884 & 3.116 & 5.8817 & 2.7701 & 280.35 & -0.3812 & 3.6188 & 8.0143 & 4.4225 \\
\hline DP3 & 380.44 & -1.4058 & 2.5942 & 5.8532 & 3.2590 & 266.05 & -0.5235 & 3.4765 & 8.1368 & 4.6603 \\
\hline DP4 & 693.74 & -1.2105 & 2.7895 & 4.5767 & 1.7872 & 704.68 & -1.2309 & 2.7691 & 4.5285 & 1.7594 \\
\hline DP5 & 354.72 & -1.995 & 2.005 & 5.5003 & 3.4953 & 355.68 & -1.8675 & 2.1325 & 5.6183 & 3.4858 \\
\hline
\end{tabular}

Light Harvesting Efficiency (LHE) and Oscillator Strength

The light harvesting efficiency (LHE), another factor which indicates the efficiency of DSSC; is the efficiency of dye to respond to the light and so it should be as high as to maximize the photo-current response $^{9}$. The oscillator strength is directly obtained from TDDFT calculations. Higher oscillator strength of three new designed sensitizers is due to better pi-conjugation. We have calculated the LHE of the main absorption peaks and then we have calculated the average LHE which is higher for the newly designed sensitizer expect Dipyridyl in DMF as shown in Table-3. These dyes will convert more light to electrical energy.

Table-3: Excitation energy (E), Light Harvesting Efficiency (LHE) and Average Light Harvesting Efficiency $\left(\mathrm{LHF}_{\text {Average }}\right)$ of dyes at B3LYP/6-311+G level of theory

\begin{tabular}{|c|c|c|c|c|c|c|c|c|}
\hline & \multicolumn{4}{|c|}{ Gas Phase } & \multicolumn{4}{|c|}{ DMF } \\
\hline System & $\mathrm{E}(\mathrm{eV})$ & $\lambda(\mathrm{nm})$ & LHE & $L H E_{a v g}$ & $E(e V)$ & $\lambda(\mathrm{nm})$ & LHE & $L H E_{\text {avg }}$ \\
\hline \multirow{3}{*}{ DP } & 3.6975 & 325.32 & 0 & \multirow{3}{*}{0.1438} & 3.8753 & 319.94 & 0.0009 & \multirow{3}{*}{0.1838} \\
\hline & 3.8539 & 321.71 & 0.0080 & & 3.9660 & 312.62 & 0.5404 & \\
\hline & 4.0406 & 306.85 & 0.4232 & & 4.0215 & 308.31 & 0.0101 & \\
\hline \multirow{3}{*}{ DP1 } & 2.9948 & 414.00 & 0.0399 & \multirow{3}{*}{0.1432} & 4.3202 & 286.99 & 0.2914 & \multirow{3}{*}{0.5787} \\
\hline & 3.3865 & 366.11 & 0.3681 & & 4.4531 & 278.42 & 0.7821 & \\
\hline & 3.4302 & 361.45 & 0.0214 & & 4.7709 & 259.87 & 0.6627 & \\
\hline \multirow{3}{*}{ DP2 } & 1.7297 & 716.80 & 0.0132 & \multirow{3}{*}{0.0102} & 3.5991 & 344.49 & 0.1284 & \multirow{3}{*}{0.4822} \\
\hline & 1.9499 & 635.86 & 0.0144 & & 4.1820 & 296.47 & 0.4031 & \\
\hline & 2.7701 & 447.59 & 0.0029 & & 4.4225 & 280.35 & 0.9151 & \\
\hline \multirow{3}{*}{ DP3 } & 2.5448 & 487.20 & 0.0025 & \multirow{3}{*}{0.1703} & 4.1322 & 300.04 & 0.4032 & \multirow{3}{*}{0.6448} \\
\hline & 3.2368 & 383.05 & 0.2828 & & 4.3653 & 284.02 & 0.7133 & \\
\hline & 3.2590 & 380.44 & 0.2255 & & 4.6603 & 266.05 & 0.8176 & \\
\hline \multirow{3}{*}{ DP4 } & 0.1711 & 7244.69 & 0.0007 & \multirow{3}{*}{0.0562} & 0.1404 & 8827.67 & 0.0069 & \multirow{3}{*}{0.0748} \\
\hline & 1.4183 & 874.20 & 0.0890 & & 1.3382 & 926.50 & 0.1234 & \\
\hline & 1.7872 & 698.74 & 0.0789 & & 1.7594 & 704.68 & 0.1002 & \\
\hline \multirow{3}{*}{ DP5 } & 2.5705 & 482.33 & 0.0299 & \multirow{3}{*}{0.3444} & 2.5902 & 478.67 & 0.11508 & \multirow{3}{*}{0.4435} \\
\hline & 2.9789 & 416.21 & 0.3517 & & 3.0304 & 409.14 & 0.51938 & \\
\hline & 3.4953 & 354.72 & 0.6517 & & 3.4858 & 355.68 & 0.69612 & \\
\hline
\end{tabular}

\section{CONCLUSION}

In conclusion, we have successfully and theoretically analyzed each of the molecules. As in thermodynamics, the spontaneous charge transfer process from the dye in an excited state to the conduction band of metal oxide needs the LUMO energy of the dye. It is a more positive potential than the conduction band energy of the metal oxide, while the HOMO energy of the dye must be more negative than reduce potential energy of the electrolyte. All newly designed dyes DP1, DP2, DP3, DP4 and DP5 were highly red compared to dipyridyl, due to solvent effects. The calculations show that all dyes can work for DSSC with $\mathrm{TiO}_{2}$, because all have LUMO's less negative than $\mathrm{TiO}_{2}$. The $\lambda_{\mathrm{G}}{ }^{\text {inject }}$ and LHE of newly designed photo sensitizers were improved by comparing the LHE of all the dyes; DP5 has higher LHE, which we recommend for DSSC with $\mathrm{TiO}_{2}$. 

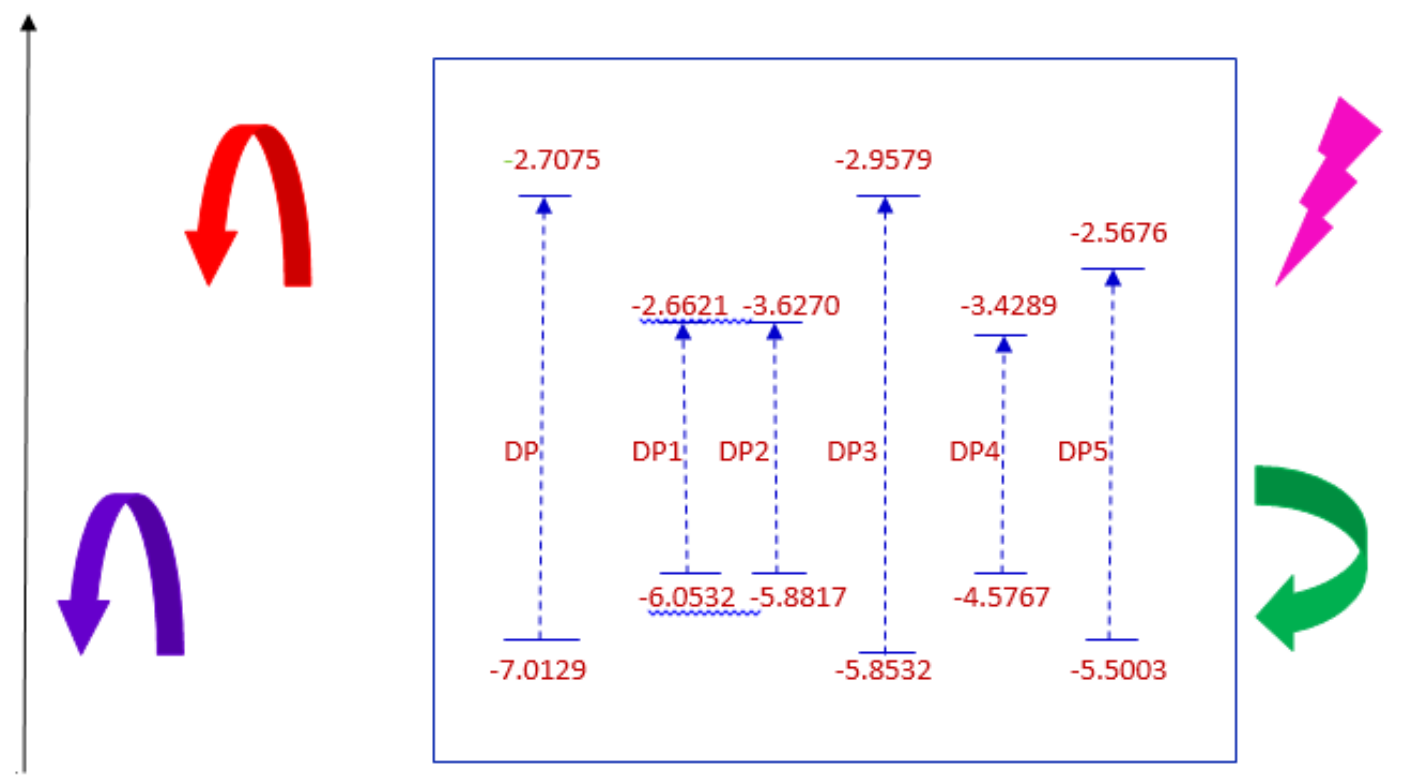

Fig.-5: Schematic energy diagram of dyes, $\mathrm{TiO}_{2}$ and electrolyte $\left(\mathrm{I}^{-} / \mathrm{I}^{3}\right)$. EHONo and ELtwo of the dyes are in gas phase
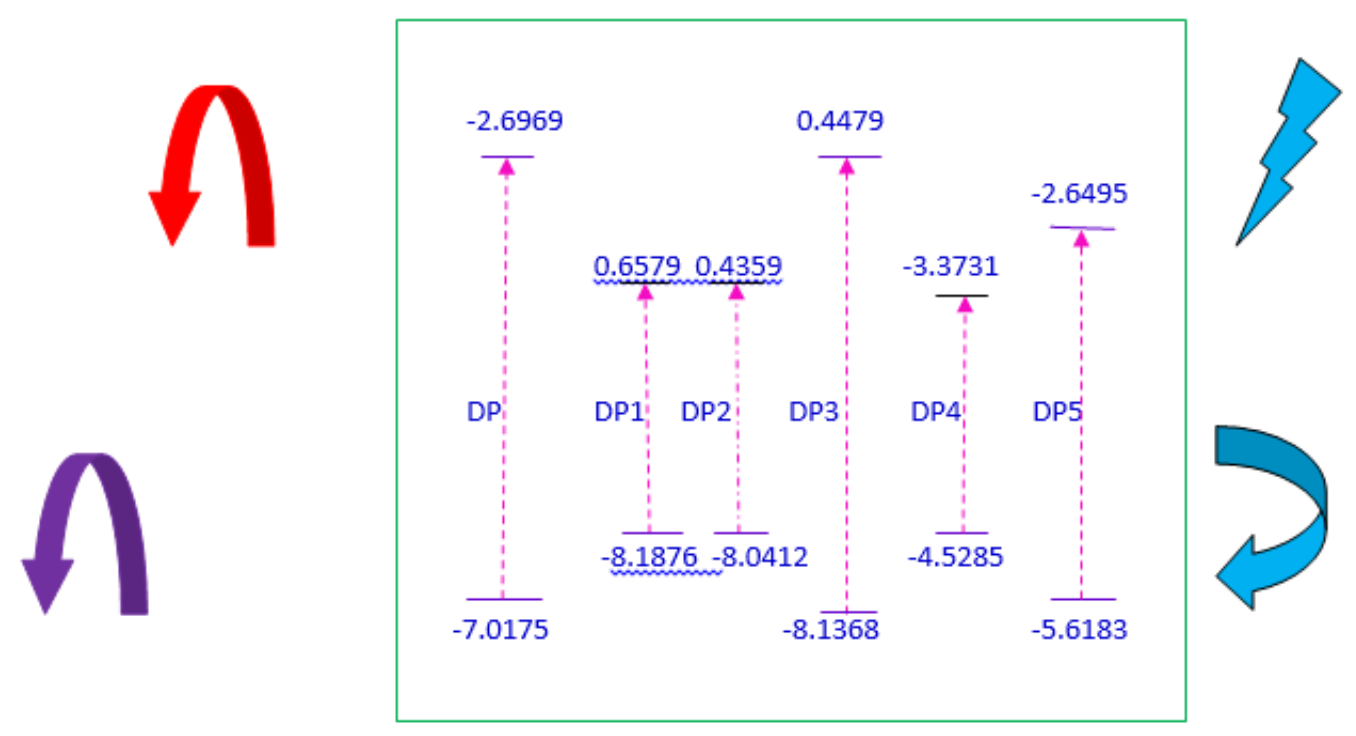

Fig.-6: Schematic energy diagram of dyes, $\mathrm{TiO}_{2}$ and electrolyte ( $\left.\mathrm{I}^{-} / \mathrm{I}^{-}\right)$. EHOMO and ELUNo of the dyes are in DMF

\section{REFERENCES}

1. B. O. Regan, and M. Gratzel, Nature 353, 737 (1991).

2. M. K. Nazeeruddin, F. De Angelis, S. Fantacci, A. Selloni, G. Viscardi, P. Liska, S. Ito, B. Takeru, and M. Grätzel, J. Am.Chem. Soc., 127, 16835 (2005).

3. Q. F. Zhang, C. S. Dandeneau, X.Y. Zhou and G. Z. Cao, Adv. Mater., 21, 4087 (2009).

4. M. J. Frisch et. al. Gaussian 09, Revision A.1. Gaussian Inc, Wallingford, CT, 2009.

5. J. A. McCleverty and T.J. Meyer, Comprehensive coordination chemistry II from biology to nanotechnology (1st ed) Amsterdam: Elsevier Pergamon, p. 1, (2004). 
RASĀYAN J. Chem.

Vol. 10 | No. 2 |613 - 620 | April - June | 2017

6. R. Katoh, A. Furube, T. Yoshihara, K. Hara, G. Fujihashi, S. Takano, S. Murata, H. Arakawa, M. Tachiya, J. Phys. Chem. B, 108, 4818 (2004).

7. Nalwa, H. S. Handbook of Advanced Electronic and Photonic Materials and Devices; Academic: San Diego, 2001

8. S. Wichien, S. Samarn, A. Vittaya, J. Photochem. Photobiol. A, 236, 35(2012).

9. Mohammad Imran Abdullah, Mohammad Ramzan Saeed Ashraf Janjua, Asif Mohammad, Sajid Ali and Mohammad Ali., Bull. Korean Chem Soc. ,34,2093(2013).

[RJC-1598/2017] 